\title{
A prática da contação de histórias por professoras da educação infantil
}

\author{
Maria Irene Miranda ${ }^{1}$ \\ Valéria Silva ${ }^{2}$
}

\begin{abstract}
RESUMO
O presente artigo versa sobre uma investigação de campo desenvolvida com professoras do segmento da educação infantil que contam histórias. A contação de história, componente primordial do universo literário, está presente nesse contexto. O objetivo do trabalho foi conhecer as concepções de contação de histórias destas docentes, analisar como a literatura é levada para as escolas, como recorrem e escolhem as obras; e ainda, identificar interfaces entre esta prática e a realidade e dos alunos. Apresentamos o delineamento da pesquisa, as descobertas e resultados alcançados definidos por dois eixos temáticos que destacam as concepções e escolhas das professoras no que tange a contação de histórias, bem como a interfaces com a realidade e demandas dos alunos. O texto aponta avanços e ambiguidades das docentes na abordagem com as histórias.
\end{abstract}

PALAVRAS-CHAVE: Literatura. Contação de histórias. Docentes. Educação infantil.

The practice of telling stories of teachers childhood education

\begin{abstract}
This article deals with a field research carried out with four teachers of the municipal education network in the segment of early childhood education that tell stories. The storytelling, a primordial component of the literary universe, is present in this context. The objective of this work was to know the conceptions of storytelling of these teachers, to analyze how literature is taken to schools, how they use and choose works; and
\end{abstract}

\footnotetext{
1 Doutora em Educação (Psicologia da Educação) pela Pontifícia Universidade Católica de São Paulo, Brasil. Uberlândia, Minas Gerais, Brasil. https://orcid.org/0000-0002-2918-8524.mirenemufu@ gmail.com.

2 Mestre em educação pela Universidade Federal de Uberlândia. Uberlândia, Minas Gerais, Brasil. https://orcid.org/0000-0001-9420-8184.valeriasilvaluiz@hotmail.com.
} 
also, to identify interfaces between this practice and reality and students. I present the outline of the research, pointing out the findings and results achieved defined by two thematic axes that highlight the conceptions and choices of the teachers regarding the storytelling, as well as the interfaces with the reality and the demands of the students; I discover through the research some ambiguities committed by the teachers in approaching the stories.

KEYWORDS: literature, storytelling, teachers, early childhood education.

$$
* * *
$$

\section{Delineamentos e caminhos da investigação}

O desejo de investigar a contação de histórias percorre os tempos escolares, perpassa a vida acadêmica e profissional de muitos docentes. $\mathrm{O}$ fascínio pelo universo das histórias possibilita galgar os caminhos da arte das narrativas; A busca pelo aprimoramento nesta arte somado as experiências em sala de aula foram, com o passar do tempo, aguçando nossas inquietações que paulatinamente foram consubstanciadas gerando o objeto de investigação: o professor da educação infantil que trabalha com a contação de histórias; tema que culminou em uma proposta de pesquisa.

Ressalte-se que o caráter pessoal do trabalho do pesquisador tem uma dimensão social, o que confere o seu sentido político. Esta exigência de uma significação política englobante implica que, antes de buscar-se um objeto de pesquisa, o pós-graduando pesquisador já deve ter pensado no mundo, indagando-se criticamente a respeito de sua situação, bem como da situação de seu projeto e de seu trabalho, nas tramas políticas da realidade social. Trata-se de saber bem, o mais explicitamente possível, o que se quer, o que se pretende no mundo dos homens. (SEVERINO, 2002, p. 146). 
Os estudos e levantamentos incidiram sobre quatro professoras de escolas municipais de uma cidade de médio porte do sudeste brasileiro, do segmento da educação infantil que divulgam suas propostas de contação de histórias nas redes sociais. O contato com as participantes ocorreu por meio de diálogos abertos e flexíveis, no decorrer de entrevistas reflexivas, quando pudemos esclarecer dúvidas, acrescentar outras questões e favorecer as interlocuções. Como acrescenta Szymanski, (2010), este instrumento combina questões abertas que conferem liberdade entre entrevistado e entrevistador sem abrir mão dos critérios e condutas investigativas inerentes à pesquisa.

Ao considerarmos o caráter de interação social da entrevista, passamos a vê- la submetida às condições comuns de toda interação face a face, na qual a natureza das relações entre entrevistador/entrevistado influencia tanto o seu curso como o tipo de informação que aparece. Como experiência humana, dá-se no "espaço relacional do conversar" [...] (SZYMANSKI, 2010, p. 11).

Agregando sentido a entrevista reflexiva utilizamos a análise documental de planos de aula das professoras; os registros apontaram dados importantes sobre o que se pretendia: conhecer as concepções de contação de histórias das professoras.

Outro instrumento utilizado na coleta de dados foi o Grupo focal, trata-se de uma dinâmica de grupo com pessoas com características em comuns, nesse caso as quatro professoras participantes, conduzidas por diálogos intermediados por um moderador que lança as questões para que se posicionem.

O moderador deve ter conhecimento sobre o assunto, a dinâmica conta também com a presença de um relator que faz os registros durante as interações. 
O trabalho com grupos focais permite compreender processos de construção da realidade por determinados grupos sociais, compreender práticas cotidianas, ações e reações a fatos e eventos, comportamentos e atitudes, constituindo-se uma técnica importante para o conhecimento das representações, percepções, crenças, hábitos, valores restrições, preconceitos, linguagens e simbologias prevalentes no trato de uma dada questão por pessoas que partilham alguns traços em comum, relevantes para o estudo do problema visado. A pesquisa com grupos focais, além de ajudar na obtenção de perspectivas diferentes sobre uma mesma questão, permite também a compreensão de ideias partilhadas por pessoas no dia - a- dia e dos modos pelos quais os indivíduos são influenciados pelos outros. (GATTI, 2005, p. 11).

As investigações tiveram por princípios a abordagem hermenêutica que nas palavras de Santos Filho (2007), consiste em compreender o significado das ações dos participantes e interpretá-las mediante um processo de movimento constante entre as partes e o todo; ou seja, entre os agentes envolvidos e seu contexto.

Do ponto de vista metodológico, a abordagem hermenêutica se encaminha dentro dos parâmetros seguintes: (a) busca esclarecer o contexto dos diferentes atores e das propostas que produzem; (b) acredita que existe um teor de racionalidade e de responsabilidade nas diferentes linguagens que servem como veículo de comunicação; (c) coloca os fatos, os relatos e observações no contexto dos atores; (d) assume seu papel de julgar e tomar posição sobre o que ouve, observa e compartilha; e (e) produz um relato dos fatos em que os diferentes atores se sintam contemplados. (MINAYO, 2010, p.167).

A partir da abordagem hermenêutica encontramos subsídios e 
respaldo na metodologia interpretativa, uma vez que nos permite compreender a realidade contínua em constante movimento, possibilita ainda confrontar os dados do fenômeno em estudo pela interação da teoria relacionada aos elementos verbais e não verbais.

Por meio de uma revisão bibliográfica cautelosa foi possível discorrer sobre os percursos da literatura desde sua origem, destacando como ocorriam a contação de histórias, a difusão e os registros em tempos antigos, e ainda abarcando a capacidade de renovação das narrativas na contemporaneidade até chegar às narrativas no contexto da educação infantil aliadas ao processo de aprendizagem.

Revisitar o referencial teórico possibilitou-me conhecer os caminhos das histórias em suas diversas configurações: anedotas, causos, narrativas, contos, lendas, poesia, prosas, fábulas, dentre outros; delineando os percursos e fronteiras dos discursos narrativos que perfazem este universo. Revisitamos a origem das narrativas e os seus contornos nos aspectos: estéticos, culturais, sociais, educacionais. Também abordamos o surgimento dos primeiros contadores de histórias, destacando como estas narrativas perpassaram espaços e tempos até os dias atuais.

$\mathrm{Na}$ organização e análise de dados, o texto foi composto por dois eixos temáticos: concepções e práticas de professoras que contam histórias e literatura na escola. O primeiro eixo teve com objetivo conhecer as concepções das professoras em relação a contação de histórias.

Ficou evidenciado que os princípios e valores das docentes incidem diretamente na metodologia, nos recursos disponíveis, no ambiente e no uso das tecnologias. O segundo eixo teve o objetivo de compreender como as obras chegam às escolas e evidenciar as interfaces com a realidade e necessidade dos alunos.

Nesse momento tornou-se evidente a influência das determinações da Secretaria Municipal de Educação na condução do processo pedagógico, assim como algumas ambiguidades das docentes na prática da contação de histórias. A seguir apresentamos a composição dos eixos temáticos, as 
inferências e descobertas geradas pela pesquisa.

\section{Concepções e práticas de professoras que contam histórias}

Apropriar- se das informações coletadas, organizar os dados, fazer o tratamento de forma sistematizada, estabelecer as devidas relações, explicitar o caráter epistemológico que responda as indagações suscitadas na pesquisa, tendo como referência metodologias e abordagens que sustentem os argumentos e inferências, constitui-se uma tarefa minuciosa que exige cautela, bem como a revisão bibliográfica.

Mas do mesmo modo como existem vários processos de levantamento de dados empíricos, existem igualmente vários modos de interpretação lógica destes dados. Trata-se dos vários métodos epistemológicos utilizáveis para a compreensão significativa dos dados reais. (SEVERINO, 2002, p.150).

A partir deste percurso, os instrumentos elencados para as análises de dados nos possibilitaram interpretar, comparar, descobrir fatos, fazer inferências e desvendar resultados. A entrevista reflexiva, a análise documental de planos de aula e a dinâmica do grupo focal, revelaram que as professoras acreditam nas abordagens com as histórias no segmento da educação infantil como algo essencial, de suma importância, uma possibilidade ímpar de marcar a vida das crianças.

Importante destacar que nos documentos oficiais como: referenciais, parâmetros e diretrizes que orientam as práticas na educação infantil a contação de histórias têm papel fundamental.

[...] ter acesso à boa literatura é dispor de uma informação cultural que alimenta a imaginação e desperta o prazer pela leitura. A intenção de fazer com que as crianças, desde cedo, apreciem o 
momento de sentar para ouvir histórias exige que o professor, como leitor, preocupe-se em lê-la com interesse, criando um ambiente agradável e convidativo à escuta atenta, mobilizando a expectativa das crianças, permitindo que elas olhem o texto e as ilustrações enquanto a história é lida. [...] (BRASIL, 1998, p.143).

As participantes da pesquisa são graduadas em pedagogia, com exceção de uma com formação em letras; as idades variam entre 38 a 46 anos; todas com experiência no exercício na função há mais de 5 anos.

Os valores e princípios que as professoras atribuem as histórias incidem diretamente em suas práticas cotidianas e concomitante geram fatores que determinam a metodologia, os recursos didáticos, o ambiente e o uso da tecnologia para efetivação da contação de histórias.

Neste sentido as docentes ajustam os recursos didáticos à metodologia por meio da preparação prévia, manuseio de livros, roda de conversa, dramatização, sondagem prévia de histórias, uso de fantoches diversos, roupas e acessórios, estabelecimento de um clima favorável, um convite às histórias.

As docentes também dispõem de recursos internos e externos que nas palavras de Machado (2004) são essenciais para a qualidade da contação de histórias; esses elementos devem combinar com a narrativa.

A intenção, o ritmo e a técnica constroem passo a passo a possibilidade da presença, a capacidade de responder criadoramente a tudo que ocorre no instante da narração, com vivacidade e confiança. Confiança na potencialidade de seus recursos externos e internos, confiança na história como um presente que ele oferece a si mesmo e à sua audiência. Estar presente é poder PRESENTEAR. (MACHADO, 2004, p. 81). 
Em relação ao ambiente, as professoras relataram como essencial a predisposição para a transformação; uma pequena sala pode adquirir as mais variadas configurações, nos espaços alternativos ocorre a mudança dos objetos e as adaptações necessárias para que a contação de histórias aconteça.

Com exceção de uma escola, as demais são casas adaptadas, as professoras exploram o quiosque, a sala de aula é remodelada retirando-se as carteiras e objetos, exploram as áreas livres, o refeitório dentre outros. Cientes da precariedade dos ambientes as docentes promovem as transformações necessárias para que a atmosfera das histórias aconteça.

No que concerne ao uso da tecnologia, é uma aliada ao trabalho das docentes que: fazem pesquisas, estudos, utilizam vídeos, usam a internet, data show, microfone; caixa de som, celular, divulgam seus trabalhos nas redes sociais, fazem postagens, etc.

A pesquisa investigou as concepções das docentes em relação a contação de histórias, elas acreditam na potencialidade contida nas narrativas, efetivam suas práticas com determinação, comprometimento e sensibilidade, estas iniciativas merecem destaque por fazer das narrativas parte de suas ações diárias; tendo em vista que no universo da educação infantil existem profissionais que não ousam trazer estas abordagens para o chão da escola.

Em consonância com as concepções das docentes, Egan (2002) destaca que as crianças devem ter acesso às histórias desde cedo, sendo assim, torna-se imprescindível a forma como o professor as conduz a este universo.

Faz-se necessário destacar que o segmento da educação infantil constitui uma fase importante também para o trabalho intelectual; nessa perspectiva inserir a literatura infantil desde a mais tenra idade contribui significativamente para a aprendizagem das crianças.

A experiência de nos sentirmos parte de um conglomerado humano que compartilha e reusa os símbolos para que o território 
da linguagem seja decifrado, expresso e habitado é que outorga um sentido profundo à literatura e essa revelação se torna patente nos primeiros anos de vida. Nessa aresta que mescla o universal e o particular e a qual nos permite reconhecer, diferenciar e construir a nós mesmos por meio de um diálogo com as páginas da cultura é que encontro uma justificativa profunda para incluir a formação literária no baú familiar de nossas crianças, como alternativa de nutrição emocional e cognitiva e como equipamento básico para habitar mundos possíveis na medida de cada ser humano. (REYES, 2010, p. 14).

Compreendendo a literatura como alternativa, as docentes favorecem às crianças o contato com este bem cultural que se manifesta das mais variadas formas: lendas, contos, prosas, poesias narrativas ou outros tantos aspectos; nestas experiências as professoras promovem interações, mediação, socialização e intersubjetividade, relações compartilhadas no encontro com as histórias.

\section{A literatura na escola}

As investigações nos possibilitaram fazer decobertas e compreender como ocorrem as escolhas das obras e como elas são inseridas nas escolas. Identificamos que as docentes abordam com frequência as narrativas, usam como critério de escolha, os eixos de trabalho da Secretaria Municipal de Educação (SME), que são as orientações curriculares para os planejamentos do trabalho docente. Dessa forma os eixos constituem ponto de partida para definição das obras literárias.

Explicitando de forma breve, a SME define quatro eixos de trabalho: natureza e sociedade, matemática, linguagem oral e escrita, autonomia e identidade, distribuídos cada qual em quatro aulas semanais que perfazem o total de dezesseis horas semanais compondo a somatória da carga horária do professor. 
Por ser assim, o professor deve contemplar estes eixos, seja individualmente ou articulados entre si, apresentando-os nos planejamentos e nos diários de classe; tal exigência incide nas ações efetivas no dia a dia em sala de aula e reflete na maneira de abordar as histórias.

No cumprimento destas prescrições as docentes não atentam para o paradoxo entre suas concepções e valores em relação as narrativas e o que realmente se efetiva no momento da prática. Quando inserem as histórias tendo como foco as determinações da SME, evidenciam-se os equívocos nas abordagens com as narrativas.

Uma característica comum às professoras, se deteve sobre o acervo, e cursos de formação docente propostos pela Secretaria Municipal de Educação; elas utilizam obras que são fornecidas pelo governo às escolas e comumente abordam as mesmas obras.

A partir do que acreditam ser o trabalho com as histórias, as professoras compreendem a dimensão da literatura como princípio de: arte, estética, fruição poética, subjetividades, etc.

Entretanto a pesquisa identificou que em várias circunstâncias essa concepção não condiz com a realidade, por exemplo, quando a literatura se prestou ao cumprimento dos eixos de trabalho, quando foi destinada a fins moralizantes e disciplinares, ou ainda quando esteve a serviço de temas específicos, culminando em finalidades utilitaristas, como atender as datas comemorativas. Essa abordagem pedagógica da literatura pode ser considerada um equívoco.

A literatura infantil, nessa medida, é levada a realizar sua função formadora, que não se confunde com uma missão pedagógica. Com efeito, ela dá conta de uma tarefa a que está voltada toda a cultura- a de "conhecimento do mundo e do ser". (ZILBERMAN, 2003, p. 29).

As docentes reafirmaram a necessidade de as histórias atenderem aos eixos de trabalho, relataram que abordam as narrativas para trabalhar 
datas comemorativas, alfabetização ou reforçar temas; não apontaram que cumprir com a exigência de articulações e finalidades atribuídas as histórias promove a fragmentação da literatura. Consideramos que, como nos mostra Oliveira (2012, p. 38), que:

A Educação Infantil não deveria envolver-se com a questão do currículo, termo em geral associado a certo percurso de escolarização vivido no Ensino Fundamental e norteado por práticas reconhecidamente fragmentadas e restritivas e centrado na ideia de disciplinas, de matérias escolares. (OLIVEIRA, 2012, p. 38).

Ainda nesse sentido Hunt (2010) nos alerta que, a literatura não pode servir de reforço ou complemento de conteúdo, não se apresenta de maneira estática, ela é significante e não significado, provoca no outro as mais variadas sensações e ilações.

É válido dizer que não existe requisito para que a criança se envolver com uma história, destarte a maneira como o professor dispõe dos recursos internos e externos e interage com o público, propicia trocas entre quem conta e quem ouve; a partir disto os ouvintes podem manifestar diferentes emoções e sensações, desencadear sentimentos de alegria, satisfação, curiosidade, criatividade; ou ainda emergir conflitos internos de angústia e tristeza, tornando latente a imaginação, a representação e o simbólico, caráter essencial da literatura.

A prática regular de ouvir histórias pode, pois, estimular todo um conjunto de capacidades cognitivas, as crianças conseguindo interpretar histórias cada vez mais sofisticadas necessariamente desenvolvem um sentido de causalidade mais apurado". (EGAN, 1994, p. 101). 
O universo literário é uma arte plural, polissêmica, representativa, é magia, simbolismo, essência. Sobre este prisma trabalhar com as histórias clássicas como: Chapeuzinho vermelho, Rapunzel, A galinha ruiva, Os três porquinhos, etc, torna-se primordial. No entanto a pesquisa evidenciou que os contos clássicos são abordados para trabalhar os eixos: identidade, linguagem oral e escrita, natureza e sociedade, matemática, comportamento, moral, as datas comemorativas. A título de ilustração, o clássico "A galinha Ruiva" abordado por uma das professoras desencadeou um projeto com diferentes atividades pedagógicas.

[...] cabe então, pensarmos detidamente sobre os critérios utilizados nas escolhas dos livros, já que essas literaturas - por serem oferecidas para crianças e jovens - não podem ser reduzidas a meros objetos pedagógicos ou a discursos utilitaristas [...]. (KHALIL E ANDDRADE, 2013, P. 5-6).

Disciplinar a literatura e pedagogizá-la pode ser algo pernicioso. Nesse sentido em seu livro Literatura em perigo, Tzedan Todorov afirma que um problema siginifacativo que vem ocorrendo no ensino de literatura nas escolas é fato de as teorias estarem se sobrepondo aos textos literários. Como abrevia o tradutor do livro, Caio Meira, no prefácio:

[...] O perigo mencionado por Todorov não está, portanto, na escassez de bons poetas ou ficcionistas, no esgotamento da produção ou da criação poética, mas na forma como a literatura tem sido oferecida aos jovens, desde a escola primaria até a faculdade: o perigo esta no fato de que, por uma estranha inversão, o estudante não entra em contato com a literatura mediante a leitura dos textos literários propriamente ditos (...) seu acesso à literatura é mediado pela forma "disciplinar" e institucional. (TODOROV, 2012, p. 10). 
Foi possível inferir que as intencionalidades das professoras em revigorar a arte de contar histórias, vislumbraram mudanças, diferentes estratégias, entretanto na prática muitas vezes as histórias culminaram em lições pontuais, pretextos e atividades específicas.

Outro apontamento explicitado na pesquisa: as docentes por uma escuta ativa e sensível ao trazer para sala de aula as histórias, procuram atender as necessidade dos alunos e demandas emergenciais, estabelecendo interfaces com suas realidades.

Modelos mais recentes de Educação Infantil mostram a importância de seus educadores serem sensíveis às necessidades pessoais e sociais das crianças, tornando-se seus parceiros especiais em situações de adptações e acolhimento, identificação e explicitação de sentimentos, ou no enfrentamento de conflitos. Essas situações, tão comuns no dia a dia da Educação Infantil, não podem mais ser consideradas fortuitas. São, ao contrário, a essência do cotidiano dos grupos infantis, e o professor deve estar preparado para participar delas e encaminhá-las. (OLIVEIRA, 2012, p.71).

As demandas emergenciais são fatos, situações e circunstâncias que surgem no cotidiano escolar e não estão prescritas no planejamento.

Considerando o contexto, as docentes certificam-se das necessidades das crianças, extraem ideias no momento da roda de conversa, organizam os planejamentos, confeccionam materiais; observam a realidade da turma no dia a dia como, por exemplo, situações de comportamento, brigas, bullyng, separação, abandono, valores como respeito, amizade, socialização, etc.

Ancoradas na dimensão do humano e escuta ativa as professoras ressaltaram a importância em ouvir as crianças, descreveram que cada turma possui características peculiares e que histórias que tratam do companheirismo, dificuldades familiares, bullyng, amizade, solidão, morte, tristeza, são comuns neste contexto. 
Para que uma estória realmente prenda a atenção da criança, deve entretê-la e despertar sua curiosidade. Mas para enriquecer sua vida, deve estimular-lhe a imaginação: ajudá-la a desenvolver seu intelecto e tornar claras suas emoções; estar harmonizada com suas ansiedades e aspirações; reconhecer plenamente suas dificuldades e, ao mesmo tempo, sugerir soluções para os problemas que a perturbam. Resumindo, deve de uma só vez relacionar-se com todos os aspectos de sua personalidade - e isso sem nunca menosprezar a criança, buscando dar inteiro crédito a seus predicamentos e, simultaneamente, promovendo a confiança nela mesma e no seu futuro. (BETTELHEIM, 2002, p. 13).

Outro fator preponderante descrito pelas docentes, se concentra no fato de as crianças analisar as narrativas, interpretar os personagens, opinar seus gostos e predileções, sentirem se entusiasmadas e motivadas ao serem protagonistas das histórias, inseridas nas tramas das narrativas.

Todas essas aprendizagens são de natureza sociocultural, portanto não ocorrem espontaneamente como decorrência do desenvolvimento biológico, mas resultam da participação de crianças em práticas socialmente circunscritas, em que ouvem histórias, lidas ou contadas, com a mediação de adultos. (BRANDÃO, ROSA, 2011, p. 35).

Sobre esta preponderância, Cademartori (1987) destaca a importância em ofertarmos obras infantis às crianças com potencial que garanta possibilidades amplas de sentido, que os interesses pedagógicos jamais sobreponham os literários.

As quatro professoras em suas abordagens com as histórias são referências para seus alunos, compreendem o significativo papel que desempenham e que incidirá definitivamente nas vidas das crianças: construção da identidade, autonomia, formação da personalidade, gosto 
estético, habilidade crítica, dentre outros.

Neste contexto o papel significativo do professor como mediador, promotor de interações e incentivador do processo de aprendizagem que envolva as temáticas com a contação de histórias exige reflexão sobre as propostas, atento as múltiplas dimensões que envolvem a formação do aluno, abarcando os aspectos emocionais, cognitivos, físicos, afetivos e sociais.

Olhar para as práticas culturais nas quais as crianças se envolvem e constroem sentidos sobre o mundo constitui boa direção para nortear o trabalho pedagógico visando a mediação de situações de aprendizagens significativas em um movimento de reflexão/avaliação constante. (OLIVEIRA, 2012, p.40).

As narrativas promovem nas rotinas diárias interações e diálogos como forma também de levar a criança a interpretar o mundo. É uma ferramenta de acesso à cultura, que se vale da interlocução do ritmo, música, oralidade, criatividade, ludicidade, imaginação e fantasia, do manuseio do livro, da exploração de diversos gêneros literários como caminho de aprendizagem às crianças.

\section{Considerações finais}

Pensar sobre a literatura e seus desmembramentos por meio de uma pesquisa permitiu analisar as concepções de professoras da educação infantil que contam histórias. Nesse sentido, o estudo revelou as concepções, valores e convicções dessas docentes sobre a contação das histórias, evidenciou como as obras são levadas para as escolas, e os critérios de definição das mesmas.

Os critérios de definição das obras precrevem os eixos de trabalhos que fundamentam a proposta pedagógica, bem como as exigências da 
Secretaria Municiapal de Educação, contemplam também as necessidades dos alunos e as demandas emergenciais que são situações, fatos e circusntâncias que ocorrem no dia a dia da sala de aula que permitem as docentes fazer escolhas de quais histórias vão abordar.

A partir destes parâmetros as professoras fazem: consulta pessoal das obras, pequisam, selecionam, partem do princípio das suas próprias experiências, além de utilizarem o material que é fornecido às escolas.

As escolas recebem do governo pela Fundação Nacional do Livro infanto-juvenil (FNLIJ) caixas de livros, como são os mesmos acervos distribuídos em todas as unidades de educação infantil comumente as docentes recorrem as mesmas obras como: "O menino e o peixinho", "Rafaela Tagarela”, "O Minhoco Apaixonado”, etc. Além das obras que recebem, as docentes abordam os clássicos infantis como "Pinóquio" e "Galinha Ruiva", e os contos de fadas.

Ficou evidenciado que as professoras ao abordar as histórias, confiam no potencial contido nelas, acreditam que levam para as crianças uma literatura de qualidade com dimensão estética, poética, simbólica e singular.

Todavia foi evidenciado que, a partir de suas concepções e princípios, as docentes contemplam essencialmente os eixos de trabalho e designam às histórias outras finalidades como: atender as datas comemorativas, execução de projetos, dentre outros.

Esse fato demostra um desafio a ser enfrentado pelas docentes, o que exige um processo de formação contínua, ou seja necessitam de uma compreensão sobre a dimensão literária que abarca a prática das histórias como patrimônio cultural, os cuidados quanto ao que é oferecido nas escolas, sugerindo análise e pesquisas constantes sobre as obras, as maneiras de abordá-las, e o real papel que a literatura deve exercer neste contexto.

Enfim, a literatura infantil faz parte do patrimônio cultural e pode contribuir de modo significativo para a formação das crianças. Para isso é preciso avançar nas discussões e confrontos sobre o fazer docente, potencializando a produção de mudanças, a construção de novas 
aprendizagens e transformações na prática social e cultural. Concordamos Goulart (2019) sobre o fato de que a arte da contação de histórias demanda

ações, atuações e interações entre o narrador, a narrativa e o seu púbico. Intercaladas entre silêncio ou musicalidae, as palavras são desenroladas em tonicidade, em tonalidades e em timbres diferenciados, compondo expressões, gestos, movimentos que são, em conjunto, orquestrados por um narrador, empenhado a conquistar o olhar atento e inebriado do seu público. (GOULART, 2019, p. 9)

A partir desse olhar empenhado em conquistar a atenção do outro o fazer docente pode inspirar, num movimento de ação e reflexão, para provocar melhorias nas abordagens com a contação de histórias, considerando a capacidade de provocar mudanças na forma de pensar, agir e sentir das crianças.

\section{Referências}

BETTELHEIM, Bruno. A Psicanálise dos contos de fadas. Trad. Arlene Caetano. 16a a ed. São Paulo: Paz e Terra, 2002.

BRANDÃO Ana C. P, ROSA, Ester C. de S. (org.). Ler e Escrever na Educação Infantil: Discutindo práticas pedagógicas. $2^{\mathrm{a}}$. ed. Belo Horizonte: Autêntica editora, 2011.

BRASIL. Ministério da Educação e do Desporto. Secretaria de Educação Fundamental.Referencial Curricular Nacional para a Educação Infantil. Brasília: MEC/SEF, 1998.

BUSSATO, Cléo. A arte de contar histórias no século XXI: tradição e ciberespaço. Petropólis, Rj:Vozes, 2006.

CADEMARTORI, Lígia. O que é literatura infantil? 4a ed.São Paulo: Brasiliense, 1987.

EGAN, Kieran. O uso da narrativa como técnica de ensino. Trad. Maria do Céu Roldão. Lisboa: Dom Quixote, 1994.

: A mente educada: os males da educação e a ineficiência educacional das escolas. Trad. Eduardo Francisco Alves. Rio de Janeiro: Bertrand Brasil, 2002. 
GATTI, Bernadete A. Grupo focal na pesquisa em ciências sociais e humanas. Brasília: Liber Livro Editora, 2005.

GOULART, Ilsa do Carmo Vieira. (org.). Ler e contar histórias: Das experiências profisisonais às vivências pedagógicas. São Carlos: Pedro \& João Editores, 2019.

HUNT, Peter. Crítica, teoria e literatura infantil. Trad. Cid Knipel. São Paulo: Cosac Naify, 2010.

KHALIL, Marisa M. G, ANDRADE, Paulo F. (org.). A literatura infantil e juvenil...ainda uma vez. Uberlândia: GPEA, 2013.

MACHADO, Regina. Acordais: fundamentos teórico-poéticos da arte de contar histórias. São Paulo. Editora cultural do livro, 2004.

MINAYO, Maria Cecília de Souza. O desafio do conhecimento: pesquisa qualitativa em saúde. $12^{\text {a }}$ ed. São Paulo:Hucitec, 2010.

OLIVEIRA, Zilma Ramos de (org.). O trabalho do professor na Educação Infantil. São Paulo: Biruta, 2012.

REYES, Yolanda. A casa Imaginária: Leitura e literatura na primeira infância. $1^{\mathrm{a}}$ ed. São Paulo: Global, 2010.

SANTOS FILHO, José Camilo dos (org.). GAMBOA, Silvio. S. Pesquisa Educacional: quantidade-qualidade. 6. ed. São Paulo, Cortez, 2007.

SEVERINO, Antônio Joaquim. Metodologia do trabalho científico. $22^{\mathrm{a}}$ ed. São Paulo: Cortez, 2002.

TODOROV, Tzvetan. A literatura em perigo. Trad. Caio Meira- $4^{\mathrm{a}}$ ed. Rio de Janeiro DIFEL, 2012.

SZYMANSKI, Heloisa (org.). A entrevista na educação: a prática reflexiva. $3^{\text {a }}$ ed. Brasília: líber Livro editora, 2010.

ZILBERMAN, Regina. A Literatura Infantil na escola. $11^{\text {a }}$ ed. São Paulo: Global, 2003.

Recebido em novembro de 2018.

Aprovado em março de 2019. 